\title{
Voluntary Agreements in the Industrial Sector in China ${ }^{1}$
}

\author{
Lynn Price, Ernst Worrell, Jonathan Sinton \\ Lawrence Berkeley National Laboratory \\ 1 Cyclotron Road, MS 90-4000 \\ Berkeley, California 94720
}

\begin{abstract}
China faces a significant challenge in the years ahead to continue to provide essential materials and products for a rapidly-growing economy while addressing pressing environmental concerns. China's industrial sector is heavily dependent on the country's abundant, yet polluting, coal resources. While tremendous energy conservation and environmental protection achievements were realized in the industrial sector in the past, there remains a great gulf between the China's level of energy efficiency and that of the advanced countries of the world. Internationally, significant energy efficiency improvement in the industrial sector has been realized in a number of countries using an innovative policy mechanism called Voluntary Agreements. This paper describes international experience with Voluntary Agreements in the industrial sector as well as the development of a pilot program to test the use of such agreements with two steel mills in Shandong Province, China.
\end{abstract}

\section{Industrial Energy Use in China}

China faces a significant challenge in the years ahead to continue to provide essential materials and products for a rapidly-growing economy while addressing pressing environmental concerns. Energy is a fundamental element of the national economy and the conditions of its use have a direct impact on China's ability to reach its sustainable development goals. China's industrial sector, which accounts for over $70 \%$ of the nation's total energy consumption each year, provides materials such as steel and cement that build the nation's roads, bridges, homes, offices and other buildings. Industrial products include bicycles, cars, buses, trains, ships, office equipment, appliances, furniture, packaging, pharmaceuticals, and many other components of everyday life in an increasingly modern society. This vital production of materials and products, however, comes with considerable problems. China's industrial sector is heavily dependent on the country's abundant, yet polluting, coal resources. Industrial production locally pollutes the air with emissions of particulates, carbon monoxide, sulfur dioxide, and nitrogen oxides, uses scarce water and oil resources, emits greenhouse gases contributing to the warming global atmosphere, and often produces hazardous and polluting wastes.

\footnotetext{
${ }^{1}$ This paper is based upon a larger report (Price et al., 2003) that provides more information on international experience with Voluntary Agreements, Chinese experience with energy efficiency policies in the industrial sector, and provides recommendations as well as spreadsheet tools and sample contracts for the development and implementation of Voluntary Agreements with the two pilot steel mills in China.
} 
Fostering innovative approaches to reduce the use of polluting energy resources and to diminish pollution from industrial production that are tailored to China's emerging market-based economy is one of the most important challenges facing the nation today.

China has a history of taking effective actions to limit industrial energy consumption. In 1980, China introduced the energy strategy of "insisting on both resource development and resource conservation with the conservation as the first priority". Numerous energyefficiency polices were adopted that successfully reduced energy use while the economy grew at a rapid pace. Through these programs China was able to decouple energy use from economic growth, allowing the nation to industrialize without draining the national budget to pay exorbitant energy costs that would have occurred without such a concerted effort (Sinton, et al., 1998). During the past 20 years, China experienced an average annual increase of $4-5 \%$ in energy consumption while maintaining average annual economic growth of $8-9 \%$, realizing the macro-goal of meeting increased energy demand half through energy development and half through energy saving (Xie, 2002). These successful programs and policies, however, were implemented during a different era in China - a time when there was nearly complete government control over the nation's major industrial producers.

Today China faces a new situation: as it moves toward a market-based socialist economy, government control is weakening and enterprises are privatizing or becoming much more heavily influenced by market pressures. Issues related domestic and international competitiveness are growing in importance. Entry into the World Trade Organization (WTO) introduces new rules and new challenges for China's industries. At the same time, production of industrial materials is growing faster than ever experienced before.

While tremendous energy conservation and environmental protection achievements were realized in the past, there remains a great gulf between the China's level of energy efficiency and that of the advanced countries of the world. Sustainable development of China will be confronted with many obstacles. On the one hand, due to the large population, China possesses a relative lack of resources, especially oil resources, and the tension between oil supply and oil demand is becoming increasingly obvious. On the other hand, there is a great deal of wasted energy and many examples of low energy efficiency. At present, China's energy consumption per unit of GDP is more than two times higher than world average and energy consumption for production of the main energy-intensive products in China is $40 \%$ higher than international consumption. Thus, sustainable utilization of natural resources has become a strategy for safeguarding the nation's long-term economic development.

The pressures of rapid industrial production growth, continued environmental degradation, and increased competition create a situation that calls for a strategicallyplanned evolution of China's industries into world-class production facilities that are competitive, energy-efficient and less polluting. Such a transition requires the complete commitment of industrial enterprises and the government to work together to transform the industrial facilities of China. 


\section{International Experience with Voluntary Agreements}

Internationally, significant energy efficiency improvement in the industrial sector has been realized in a number of countries using an innovative policy mechanism called Voluntary Agreements. Over 300 environmental Voluntary Agreements have been negotiated between national governments and industry in Europe alone (Paton, 2002). The International Energy Agency has identified two broad categories of Voluntary Agreements: "(1) informal programmes, self-commitments and declarations, where the parties entering into the action with the government set their own targets and often do their own monitoring and reporting; and (2) more formal voluntary approaches where there is essentially a contract between the government and industry, or negotiated targets with commitments and time schedules on the part of all participating parties" (IEA, 1997a). In its review of 350 voluntary actions and programs, the International Energy Agency found that "past and present experiences with voluntary actions show that, properly designed and implemented, they can achieve stated objectives, sometimes even exceeding those of minimum regulatory standards, and help integrate economic and environmental goals"(IEA, 1997a)

Voluntary Agreements typically have a long-term outlook, covering a period of five to ten years, so that strategic energy-efficiency investments can be planned and implemented. A key element of Voluntary Agreements is that they focus the attention of all actors on energy efficiency or emission reduction goals. A recent analysis of seven Voluntary Agreement programs in Europe and the U.S. found that the programs could be attributed with about $50 \%$ of the observed energy-efficiency improvement or emissions reductions (Dowd et al., 2001). For example, in The Netherlands the historical energy intensity improvement rate of about $1 \%$ per year was more than doubled during the 10year period covered by the industrial Voluntary Agreement program (Kerssemeeckers, 2002).

In addition to direct energy savings, there are also important medium and long-term impacts associated with this policy mechanism including changes of attitudes and awareness of managerial and technical staff regarding energy efficiency; addressing market, institutional, regulatory, and other barriers to technology adoption and innovation; fostering market transformation to establish greater potential for sustainable energyefficiency investments; promoting positive dynamic interactions between different actors involved in technology research and development, deployment, and market development; and facilitating cooperative arrangements that provide learning mechanisms within a sector or industry to combine knowledge and develop new competencies in industry (Dowd et al., 2001; Delmas and Terlaak, 2000). These characteristics of Voluntary Agreements are what distinguish them from other energy-saving policies; changes in attitudes and approaches coupled with reducing barriers to innovation and technological change lead to greater overall energy savings than have been seen in other market-based energy-efficiency approaches in the industrial sector.

Based on experience to date, the lessons learned for designing and implementing Voluntary Agreements show that a comprehensive assessment of enterprise energy- 
efficiency potential as well as ambitious but realistic targets that are beyond "business-asusual" and specific timetables for achieving those targets are essential. In addition, clear monitoring guidelines, that include evaluation of progress using physical energy intensity measurements, and independent verification of progress, must be implemented. Finally, long-lasting government support in the form of policies and programs that assist industries in implementing energy-efficiency improvements and reaching their targets are essential (Blok, 2000). A recent analysis of five industrial sector Voluntary Agreement programs concluded that "the effectiveness of Voluntary Agreements can be seen as strongly dependent on the accompanying policy mix and the supporting framework which has to be adapted to the specific conditions" of the participating industries (Krarup and Ramesohl, 2000). In The Netherlands, experience showed that the cost to the government for implementing the Voluntary Agreement supporting policies was almost one-third less than the costs for providing direct subsidies to industry for purchase of energy-efficient equipment (Blok, 2002).

The essential components of the process of reaching a Voluntary Agreement are the assessment of the energy-efficiency potential of the participants as well as target-setting through a negotiated process. Participation by industries is motivated through the use of "carrots" and "sticks", which refers to incentives and disincentives. Supporting programs and policies (the "carrots"), such as enterprise audits, assessments, benchmarking, monitoring, information dissemination, and financial incentives all play an important role in assisting the participants in meeting the target goals. Some of the more successful Voluntary Agreement programs are based on some reduction of environmental regulations or taxes (the "sticks") for participants. Overall, international experience shows that Voluntary Agreements are an innovative and effective means to motivate industry to improve energy efficiency and reduce related emissions, if implemented within a comprehensive and transparent framework (IEA, 1997a; IEA, 1997b).

\section{Introducing Voluntary Agreements in China's Industrial Sector}

The China Sustainable Energy Program (CSEP) of the Energy Foundation, in conjunction with China's State Economic and Trade Commission (SETC) ${ }^{2}$ and the China Energy Conservation Association (CECA), launched a program to evaluate and develop an innovative energy-efficiency policy for China's industrial sector in late 1999. After assessing China's existing policies and guidelines for energy conservation as well as international advanced energy efficiency policies, the project leaders as well as the panel of experts convened to provide advice regarding the selection of a policy mechanism, decided to further study the applicability of Voluntary Agreements to China. Given their significant success in improving energy efficiency in other countries, Voluntary Agreements based on the negotiated agreements model were chosen by SETC as a new policy mechanism to test in China's industrial sector where the movement toward a market economy is demanding innovative methods for supporting and transforming essential enterprises. Analysis of the potential for energy efficiency improvement in

\footnotetext{
${ }^{2}$ During the March 2003 People's Congress, SETC was divided and merged with other Chinese government agencies. The portion of SETC involved with this project will in the future be in the State Development and Reform Commission (SDRC).
} 
various energy-intensive industrial sectors in China led to the choice of the iron and steel industry for a pilot project to evaluate this new concept. Jinan Iron and Steel Company (Jigang) and Laiwu Iron and Steel Company (Laigang) were chosen to be the first steel enterprises to test this innovative policy mechanism. The pilot will be directed by Economic Trade Commission (ETC) of Shandong Province and will be undertaken with the participation of independent organizations such as CECA, as well as the two pilot enterprises.

One objective of the pilot Energy Conservation Voluntary Agreement in Shandong Province is to provide the participants in the pilot with the tools and conditions required for successful implementation of a Voluntary Agreement. A further objective is to provide a template for the development of Voluntary Agreements as a national level industrial sector policy. Voluntary Agreements are also being tested within the United Nations Development Program (UNDP)/Global Environmental Facility (GEF) project on Energy Conservation and Greenhouse Gas Emission Reduction in Chinese Township and Village Enterprises, the State Environmental Protection Agency (SEPA) China Environmental Friendly Facility project, the China Iron and Steel Association (CISA) project on Implementing Energy Conservation Voluntary Agreements in the Chinese Steel Industry, the Beijing University Study on Policy Measures for Voluntary Agreements on Energy Saving and Pollution Reduction and is an element in the United Nations Development Program (UNDP) End-Use Energy Efficiency Program in China.

\section{Designing the Shandong Province Energy Conservation Voluntary Agreement Pilot Project}

This Pilot Project was developed collaboratively with representatives from the Jigang and Laigang steel enterprises, SETC and the Shandong ETC. ${ }^{3}$ International experts visited the participating steel enterprises and held discussions with representatives from these enterprises as well as with representatives of the Shandong ETC in May, 2000. A workshop on Voluntary Agreements for China's Industrial Sector: Integrating International Experiences into Designing a Pilot Program was held in Beijing in February 2001 in which international experts provided detailed descriptions of successful Voluntary Agreement programs in other countries and worked with the Pilot Project participants to refine their roles and responsibilities within the pilot. Further meetings with the Pilot Project participants, as well as a one-week workshop on Voluntary Agreements for China's Industrial Sector: Designing an Energy Conservation Voluntary Agreement Pilot Project in the Steel Sector in Shandong Province in The Netherlands in July 2002, has resulted in the design of the Pilot Project outlined in this report.

Designing an Energy Conservation Voluntary Agreement pilot policy program for China's industrial sector involves drawing from the successful elements of the energyefficiency programs and policies China had during the 1980s in order to develop a policy

\footnotetext{
${ }^{3}$ Jiang Yun of the China Energy Conservation Association has directed this collaboration. International experts who have participated in development of the Pilot Project are Lynn Price, Ernst Worrell, and Jonathan Sinton of Lawrence Berkeley National Laboratory (USA), Kornelis Blok and Dian Phylipsen of Ecofys (The Netherlands), and Wil Nuijen of Novem (The Netherlands).
} 
more similar to those of current Voluntary Agreement programs in developed countries. Such a policy program must take into account unique, China-specific conditions such as rapid economic growth, the need to improve environmental quality, the need to maintain employment levels, and the need to improve the competitiveness of enterprises in light of the WTO accession.

\section{Setting Energy Efficiency Targets}

In negotiated Voluntary Agreements, energy-efficiency targets are set through a process in which the government and enterprises negotiate the target level based on detailed evaluations of the potential for energy-efficiency improvement in each enterprise. For the pilot program, the energy-efficiency assessment involves determination of current energy consumption and energy intensity by process of the pilot iron and steel enterprises. Once this has been calculated, the energy-efficiency potential is calculated by comparing the energy intensity for each pilot enterprise with benchmark energy intensities that represent state-of-the-art iron and steel mills. The energy efficiency potential is determined by identification of inefficient processes within each enterprise and identification of technologies and measures that could be implemented to improve the energy efficiency of the enterprise, based on availability of technologies and cost-effectiveness criteria. The potential energy intensity reductions associated with implementation of these technologies and measures are estimated to determine the achievable energy-efficiency potential, which is in turn used to set the Energy Conservation Voluntary Agreement pilot project targets.

The energy efficiency targets are set by first developing the business-as-usual situation and then, using the information from the assessment of enterprise energy-efficiency improvement potential, calculating the additional energy efficiency improvement that could be achieved with the Voluntary Agreements. Once the targets are formulated by the enterprises, they are evaluated by CECA and the Technical Team of experts to determine if they are realistic, yet ambitious, given the results of the energy-efficiency potential assessment as well as the supporting policies offered by the government.

\section{Establishing Supporting Policies}

While the enterprises are assessing their energy-efficiency potential, the Shandong ETC formulates a list of possible supporting policies that can be offered to the participating enterprises to assist them in achieving their energy-efficiency targets. Supporting policies, such as information dissemination, government and public recognition, audits and assessments, exemption from taxes or regulations, and financial assistance and incentives are the key motivational element to encourage enterprises to participate fully in the Voluntary Agreement program.

Shandong ETC selected potential supporting policies that are suitable for China's conditions and that will promote enterprises' participation in the Voluntary Agreement program, as well as aid enterprises to achieve the energy-conservation targets. The supporting policies are: "1) give priority consideration to the two pilot enterprises under 
existing preferential policies, 2) coordinate the provision of guarantees by the provincial guarantee company for loans and other financial activities required for energy-efficiency projects at the pilot enterprises, 3) use various media to publicize the energy-conservation achievements and contributions of the pilot enterprises, 4) organize intermediary organizations to provide the pilot enterprises with policy, technical, management, and other advice and services, and 5) upon evaluation, exempt the pilot enterprises from monitoring of the status of energy utilization" (Shandong ETC, 2003). In addition to these supporting policies offered by the local government, the national level SETC will be requested to provide the following supporting policies: "1) for energy-conservation benefits realized through energy-conservation projects, and in accordance with resources comprehensive-utilization policy, investigate and propose recommendations for preferential policies to encourage energy conservation, 2) give priority support to projects undertaken by the pilot enterprises that fulfill the criteria set by national preferential policies, 3) grant a portion of research and development costs for projects undertaken by the pilot enterprises that have significant results in energy and resource conservation and comprehensive utilization, short payback times, and outstanding economic and social benefits, to support enterprises to carry out energy-conservation research and development, 4) give priority to the pilot enterprises when bringing in foreign investment capital, 5) award pilot enterprises the honorable title of China Energy-Efficiency Voluntary Agreement Pilot Enterprise" (Shandong ETC, 2003).

\section{Signing the Voluntary Agreement}

Once the energy conservation targets have been set and the supporting policies have been established, the enterprises and the Shandong ETC will sign the voluntary agreement. The voluntary agreement contract has been designed based on examples of such contracts used in The Netherlands and the U.K. The signing of the Shandong Province Pilot Project Voluntary Agreement is scheduled for Spring 2003.

\section{Implementation of the Voluntary Agreement}

Implementation of the Energy Conservation Voluntary Agreement will begin with the development of an Energy Conservation Plan by each enterprise that outlines the steps that will be taken to reach their targets. Once the Energy Conservation Plan is developed, CECA and the Technical Team will evaluate the Plan to ensure that it outlines the required energy-efficiency improvements to reach the targets. While the enterprise is developing the Energy Conservation Plan, Shandong ETC and SETC will take the necessary actions to ensure that the supporting policies are in place and that the enterprise can take advantage of them during the implementation of the Energy Conservation Plan. The implementation of the Energy Conservation Plan is in two periods: from start of the Voluntary Agreement to 2005 and, upon evaluation of the success of the first phase, from 2005 to 2010. During the two periods, the enterprise will implement the measures outlined in the Energy Conservation Plan. If needed, CECA and the Technical Team can provide technical support to the enterprises during the implementation of the Energy Conservation Plan. 
At the end of each year, the enterprises will submit a annual reports that provide detailed information on their energy-efficiency improvement progress. In addition to these annual evaluations, interim and final evaluations of the results of the implementation of the Energy Conservation Plan will be performed in 2005 and 2010, respectively. The evaluations will determine if the target has been met. Following the interim and final evaluations in 2005 and 2010, all parties will decide whether to proceed. In 2005, this will involve deciding to develop 2010 targets and Energy Conservation Plans for 2010. In 2010, this will involve deciding whether to proceed with a new Energy Conservation Voluntary Agreement. At the conclusion of the Energy Conservation Voluntary Agreement period, SETC or Shandong ETC will awards the enterprise according to its performance, honoring it with special titles as well as providing media publicity. Further, in meetings and conferences to promote the exchange of enterprise experience, the enterprise can use its own situation to make recommendations to others interested in Voluntary Agreements. CECA and the Technical Team can use their experience in the evaluation of the pilot program to suggest promotion ideas, suggest changes to improve the effectiveness and efficiency of the Voluntary Agreements, and demonstrate that the concept of Voluntary Agreements is feasible in different sectors and regions in China.

\section{Lessons Learned}

Preliminary lessons learned from the development of the Shandong Province Enterprise Energy-Efficiency Voluntary Agreement Pilot are that while the general concepts of negotiated agreements and of the value of energy-efficiency improvement in industry were easily understood and accepted by the Chinese involved in this project, more specific components of the successful Voluntary Agreements from around the world were not immediately understood or ultimately adopted.

Historically, Chinese industry has operated under annual quotas for energy consumption that were accompanied by fines and penalties if exceeded. Voluntary Agreements, on the other hand, move away from this concept to a focus on long-range planning where annual energy-efficiency progress may fluctuate but ultimately the targets are met in the long run. In the Shandong Province pilot, however, this concept is completely missing; the pilot plan outlines annual targets for 2003 and 2005, accompanied with the threat of fines for exceeding the quotas. The pilot plan does include targets for 2010 but rather allows for the development of further long-term pilots of 5 and 10 years duration after completion of this pilot. The technical experts also advocated the use of a single, comprehensive energy-efficiency measurement system called the Energy Efficiency Index which is used in the Dutch Long-Term agreements. The Shandong Province pilot, however, requests each enterprise to provide 11 somewhat confusing measurements of energy-efficiency annually, relying heavily on more familiar indicators. Finally, while some of the supporting policies were established prior to the development of the targets, other supporting policies were not set but rather were advocated as possible policies that the central government could provide. This gives the enterprises no certainty regarding these polices and leads to a situation where relatively weak targets were set for 2005 . 
On the positive side, in addition to understanding the general concept of Voluntary Agreements and including all of the essential elements in the pilot project design, the Shandong pilot project has extended the energy conservation Voluntary Agreement into the area of environmental pollutants, requesting the enterprises to provide data on their sulfur dioxide and carbon dioxide emissions annually. This is an important link to be made in China, where the drivers for adoption of energy-efficient technologies include the reduction of local, regional, and global pollutants as well as reduction of energy consumption. Also, introducing a new policy mechanism can be a long process when dealing with multiple levels of government as well as members of industry that are unclear on the benefits they will accrue from the policy. The educational and motivational aspects of such an effort cannot be understated.

\section{Conclusions}

Internationally, Voluntary Agreements have been shown to result in increased energy efficiency, with the more successful programs even doubling the autonomous energy efficiency improvement rates. The Shandong Province Enterprise Energy-Efficiency Voluntary Agreement Pilot is the first step in evaluating the use of this innovative industrial sector energy-efficiency policy mechanism in China. Lessons learned from the development and subsequent implementation of this pilot will be valuable for the myriad emerging efforts to use Voluntary Agreements to improve the energy efficiency of China's industrial sector.

\section{Acknowledgments}

This project was conducted by the China Energy Conservation Association under the direction of State Economic and Trade Commission (SETC) P.R. China Department of Resources Conservation and Comprehensive Utilization for China Sustainable Energy Program. This project was sponsored by the China Sustainable Energy Program of the Energy Foundation. Significant technical support for this project was provided by Lawrence Berkeley National Laboratory. Support for Lawrence Berkeley National Laboratory was provided by the China Sustainable Energy Program of the Energy Foundation under contract number DE-AC03-76SF00098. The authors also acknowledge the invaluable assistance of Wil Nuijen of Novem in the Netherlands, as well as Kornelis Blok and Dian Phylipsen of Ecofys in the Netherlands throughout this project. Finally, the authors would like to thank the members of the Chinese Policy Review Team for its guidance during this project.

\section{References}

Blok, K., 2000. "Experiences with Long Term Agreements on Energy-efficiency Improvements in the European Union," Presentation at the Workshop on Learning from International Best Practice Energy Policies in the Industrial Sector, May 22-23, 2000, Beijing.

Blok, K., 2002. "Establishing Targets for Energy Consumption in Energy-intensive Industries: Examples," Presentation at the Workshop on Voluntary Agreements for 
China's Industrial Sector: Integrating International Experiences into Designing a Pilot Program, Beijing, February 25-27, 2002.

Delmas, M. and Terlaak, A., 2000. "Voluntary Agreements for the Environment: Innovation and Transaction Costs," CAVA Working Paper 00/02/13, February.

Dowd, J., Friedman, K, and Boyd, G., 2001. "How Well Do Voluntary Agreements and Programs Perform At Improving Industrial Energy Efficiency," Proceedings of the 2001 ACEEE Summer Study on Energy Efficiency in Industry. Washington, DC: American Council for an Energy-Efficient Economy.

International Energy Agency, 1997a. Voluntary Actions for Energy-Related $\mathrm{CO}_{2}$ Abatement. Paris: OECD/IEA.

International Energy Agency, 1997b. Voluntary Approaches for Mitigating Greenhouse Gas Emissions. Conference Proceedings, Bonn, Germany 30-31 October 1995. Paris: $\mathrm{OECD} / \mathrm{IEA}$.

Kerssemeeckers, M., 2002. The Dutch Long-Term Voluntary Agreements on Energy Efficiency Improvement in Industry. Utrecht, The Netherlands: Ecofys.

Krarup, S. and Ramesohl, S., 2000. Voluntary Agreements in Energy Policy Implementation and Efficiency: Final Report. Copenhagen: AKF.

Paton, B., 2002. "Voluntary Environmental Initiatives and Sustainable Industry," in ten Brink, P., ed., 2002. Voluntary Environmental Agreements: Process, Practice and Future Use. Sheffield, UK: Greenleaf Publishing Ltd.

Price, L., Jiang, Y., Worrell, E., Du, W., Sinton, J., 2003. Development of an Energy Conservation Voluntary Agreement Pilot Project in the Steel Sector in Shandong Province: Project Report to the State Economic and Trade Commission People's Republic of China. Berkeley, CA: Lawrence Berkeley National Laboratory (LBNL51608), http://ies.lbl.gov/iespubs/ieuapubs.html

Shandong Economic and Trade Commission, 2003. Shandong Enterprise EnergyEfficiency Voluntary Agreement Pilot Plan. Jinan, Shandong Province, China.

Sinton, J.E., Levine, M.D., and Wang, Q., 1998. "Energy Efficiency in China: Accomplishments and Challenges," Energy Policy, Vol. 26, No. 11: 813-829.

Xie Xuren, Vice Director of SETC, 2002. Opening address for 2002 China International Energy and Environmental Protection Exhibition \& Workshop, Beijing, November 5, 2002. 